\title{
New possibilities for phase-variation structural diagnostics of multiparametrical monocrystalline systems with defects
}

\author{
V.B. Molodkin ${ }^{1}$, V.Yu. Storizhko ${ }^{2}$, V.P. Kladko ${ }^{3}$, V.V. Lizunov ${ }^{1}$, A.I. Nizkova ${ }^{1}$, O.Yo. Gudymenko ${ }^{3}$, \\ S.I. Olikhovskii ${ }^{1}$, M.G. Tolmachev ${ }^{1}$, S.V. Dmitriev ${ }^{1}$, I.I. Demchyk ${ }^{1 *}$, E.I. Bogdanov ${ }^{1}$, B.I. Hinko ${ }^{1}$ \\ ${ }^{1}$ G. Kurdyumov Institute for Metal Physics, NAS of Ukraine, \\ 36, Academician Vernadsky Blvd., 03142 Kyiv, Ukraine \\ ${ }^{2}$ Institute of Applied Physics, NAS of Ukraine, \\ 58, Petropavlivs'ka Ave., 40000 Sumy, Ukraine \\ ${ }^{3} V$. Lashkaryov Institute of Semiconductor Physics, NAS of Ukraine, \\ 41, prosp. Nauky, 03680 Kyiv, Ukraine \\ *Correspondent author e-mail: rudnytskaya@ukr.net
}

\begin{abstract}
Fundamental new features and physical nature of possibilities for purposeful influence of interrelated variations in different experimental conditions on changes of the selectivity of sensitivity of azimuthal dependence of the total integrated intensity dynamical diffraction to various types of defects in single crystals have been determined. As a result, the efficiency of the previously developed phase-variation principles of diagnostics has been improved. The proposed approach enabled us to demonstrate the presence of additional types of defects in the single crystals under study and to determine the defects parameters (sizes and concentrations). It makes it possible to obtain additional sensitivity and informativeness for phase-variation structure multiparametrical non-destructive diagnostics of monocrystalline systems with defects of various types.
\end{abstract}

Keywords: dynamical diffraction, X-ray irradiation, phase-variation diagnostics, azimuthal dependence, defects.

https://doi.org/10.15407/spqeo24.01.005

PACS 61.05.cc, 61.05.cf, 61.05.cp, 61.72.Dd, 81.40.Ef

Manuscript received 29.12.20; revised version received 22.01.21; accepted for publication 10.02.21; published online 09.03.21.

\section{Introduction}

Creation of materials with new properties necessary for practical application requires an appropriate level of experimental diagnostic methods to control the structure of developed materials. The important role for realization of these purposes is played non-destructive diffractometric methods.

As known, the most detailed information about characteristics of defects in crystals can be obtained from distributions of the diffuse scattering intensity in the reciprocal lattice space [1-3]. However, measuring these maps of the reciprocal space requires the complicated instrumentation (see, e.g., [26-31]). In addition, an important requirement for diagnostic methods is their rapidity, i.e., the time required for measurements. Obviously the diagnostic method is more convenient, when the specified time is shorter, allowing to study a larger number of samples for a fixed period of time.

The rapidity of diagnostics of monocrystalline systems can be increased using the methods of dynamical diffractometry. For example, in $[10,11]$ it was shown that the dispersion mechanism of the sensitivity inherent to the dynamical scattering patterns to structural imperfections also provides the appearance of sensitivity to structural imperfections of their individual integral characteristics. The measurement of dependences of the total integrated intensity of dynamical diffraction (TIIDD) on smoothly varying diffraction conditions for the selected combinations of fixed values of the parameters for remaining experimental conditions with the subsequent joint processing of the results enables to quantitatively determine defect structure characteristics of single crystals [12].

Among the methods of TIIDD, the one of azimuthal dependences of TIIDD is used. The integrated X-ray diffraction intensities were measured by A.W. Stevenson for the extended-face specimens as a function of azimuthal angle for the semiconductor crystals and epitaxial layers [13]. It was shown that interpretation of these results, in terms of kinematical and perfect-crystal dynamical X-ray diffraction theories, provides a measure of perfection of the crystal under investigation. However, interpretation of some results requires consideration of extinction effects and their dependence on asymmetry. 
The integrated reflection power azimuthal dependences of imperfect silicon crystals were also measured and investigated in the asymmetric Bragg diffraction geometry [14-17].

Various theoretical approaches were developed to describe the integrated intensities of dynamical diffraction. These approaches were measured in the Laue diffraction geometry for imperfect crystals with defects [18-22]. Dederichs proposed a simple heuristic formula in the semi-kinematical method. It describes the integrated intensities of dynamical X-ray diffraction measured in the Bragg diffraction geometry for the fastneutron-irradiated copper crystals [23, 24]. The statistical dynamical theory of X-ray diffraction by the imperfect single crystals was developed to characterize randomly distributed Coulomb-type defects of arbitrary sizes in both Laue and Bragg diffraction geometries [25, 16].

In articles [26-29], the azimuthal dependences method was also used for the diagnostics of defect structure of single crystals. The measurements were performed for the Bragg geometry of diffraction, reflections $\mathrm{Si}$ (220), (440) and (660), radiation $\mathrm{Mo} K_{\alpha}$. In these papers, the theoretical model was developed, which made it possible to determine the presence of defects: 'large' (the average radius of which exceeds the extinction length) randomly distributed dislocation loops (RDDL) and the disturbed surface layer (DSL). In addition, the parameters of defects were determined: concentration $c$ and average radius $R$ of dislocation loops, the thickness of the absorbing sublayer of DSL $t_{\mathrm{am}}$, the parameter $k$ describing the degree of deformation of the kinematically scattering sublayer of DSL, and the thickness of this sublayer, which was in proportion to $k$. Also, the profile of 'large' RDDL distribution over the sample depth was ascertained. These results were obtained due to proposed in $[10,11]$ phase-variation conception requiring realization of these variations under the experimental conditions, which ensures the main contribution to the intensities sequentially for each type of defects. Thereby, the contribution from defects of the certain type should exceed the total contribution from other types of defects or be simply the maximum possible.

However, according to the results of [30], Czochralsky-grown silicon single crystals can contain, besides 'large' RDDL, also 'small' RDDL with the average radius $R=0.02 \mu \mathrm{m} \sim 0.003 \Lambda$. The presence in the single crystal with 'large' RDDL both kinematically scattering sublayer and 'small' RDDL equally generates the additional TIIDD increase, and this increasing is proportion to $k$ and 'small' defects concentration $c_{\mathrm{sm}}$. As a result, the diagnostics becomes more complicated, since TIIDD for the case of large $k$ and zero concentration of 'small' defects $\left(c_{\mathrm{sm}}=0\right)$, that took place in [26-29] and TIIDD for the case of significantly smaller $k$ and non-zero $c_{\text {sm }}$ can be equal. However, the contribution of DSL to the intensity cannot be determinative under the experimental conditions considered in [26-29]. This is caused by anomalous contribution of diffuse scattering in those experiments. The experimental conditions of [26-29] enabled to realize the main contribution either from 'large' RDDL or from the rest defects of other types due to the discovered asymmetry effect of the contribution from 'large' RDDL in TIIDD and corresponding variations of the experimental conditions. However, it was not possible to separate the commensurable contributions from DSL and from 'small' RDDL by variation of the experimental conditions. This reason leads to necessity of searching a new extended set of experimental data to solve the diagnostic problem.

The aim of this work was to develop a diagnostic method for determination of parameters of one more type of defects in single crystals, namely, the 'small' dislocation loops.

\section{Experimental results and their analyses}

In this article, we develop, optimize and prepare for practical application new improved possibilities of the proposed in $[10,11]$ phase-variation approaches to the nondestructive structure diagnostics of multiparametrical systems. The experiments were carried out using the Panalytical Philips X'Pert PRO diffractometer (V. Lashkaryov Institute of Semiconductor Physics, NAS of Ukraine) for Si single crystals. All calculations presented in this article are based on the theoretical model proposed in [31]. In this model, the coherent dynamical effects of the multiple scattering of the non-coherent (efficiently) diffuse waves by the periodical ('in average') component of crystal polarizability were taken into account. In [2629], it was shown that the account of the 'large' defects can be significant even for the integrated intensities. However, in the present work the effect of the interference absorption of the diffuse scattering (analogues to Borrmann effect in the perfect crystal) is taken into account additionally to the dynamical effect of the total reflection in the diffuse scattering. It is well-known that the Borrmann effect is weak in the case of the Bragg geometry of scattering by perfect crystals due to the small depth of the existence of the dynamical wave fields. Nevertheless, the Borrmann effect can be more strong and observed even for the integrated intensity in the single crystals with defects for the Bragg diffraction geometry, but only for the diffuse scattering waves due to the essentially higher depth of their existence (of the order of absorption depth), than the depth of coherent wave existence (of the order of extinction length).

The formulated aim can be achieved using an additional experimental data set with reduced contribution of the diffuse scattering to TIIDD due to the decreasing radiation absorption length, namely, by additional measuring the azimuthal dependences of TIIDD for the Bragg geometry of diffraction and reflections (220), (004), (224), (440) of radiation $\mathrm{Cu} K_{\alpha}$. These measurements are also perspective for correction of the parameters of 'large' RDDL, DSL parameters and for determination of the distribution profile of RDDL.

Figs 1 and 2 show the azimuthal dependences of TIIDD for the crystal with defects normalized by the azimuthal dependences of IIDD for the perfect crystal $(\rho)$. The azimuthal dependences were calculated without and with account of the presence of 'small' RDDL. 


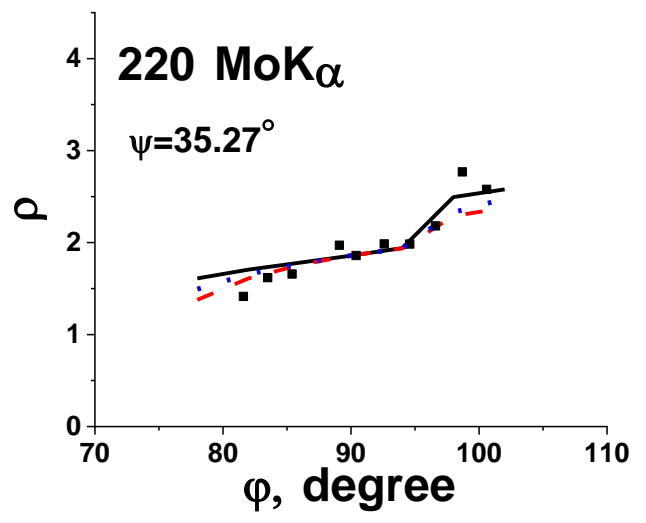

Fig. 1. The normalized azimuthal dependences of TIIDD ( $\rho)$ for Bragg reflections (220), radiation $\operatorname{Mo} K_{\alpha}$. The solid line shows the results of calculation at $t_{\mathrm{am}}=0.75 \mu \mathrm{m}, k=0.064$, $R_{\text {big loops }}=20 \mu \mathrm{m}, c_{\text {big loops }}=5 \cdot 10^{-18}$; dash line shows the results of calculation at $t_{\mathrm{am}}=0.75 \mu \mathrm{m}, k=0.004, \quad R_{\text {big loops }}=20 \mu \mathrm{m}$, $c_{\text {big loops }}=5 \cdot 10^{-18}, R_{\text {small loops }}=0.02 \mu \mathrm{m}, c_{\text {small loops }}=8.15 \cdot 10^{-10} ;$ dot line shows the results of calculation at $t_{\mathrm{am}}=0.75 \mu \mathrm{m}, k=0.033$, $R_{\text {big loops }}=20 \mu \mathrm{m}, \quad c_{\text {big loops }}=5 \cdot 10^{-18}, \quad R_{\text {small loops }}=0.02 \mu \mathrm{m}$, $c_{\text {small loops }}=4.172 \cdot 10^{-10} ;$ markers are the experimental data.

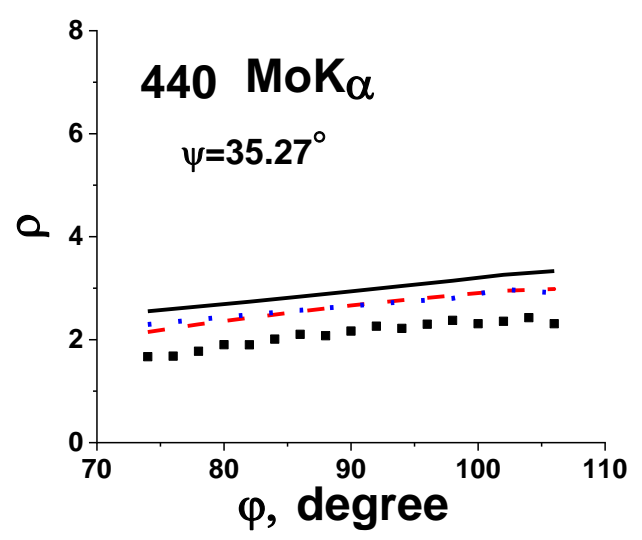

Fig. 2. The normalized azimuthal dependences of TIIDD $(\rho)$ for Bragg reflections (440), radiation $\operatorname{Mo} K_{\alpha}$. The solid line shows the results of calculation at $t_{\mathrm{am}}=0.75 \mu \mathrm{m}, k=0.064$, $R_{\text {big loops }}=20 \mu \mathrm{m}, c_{\text {big loops }}=5 \cdot 10^{-18}$; dash line shows the results of calculation at $t_{\mathrm{am}}=0.75 \mu \mathrm{m}, k=0.004, R_{\mathrm{big} \text { loops }}=20 \mu \mathrm{m}$, $c_{\text {big loops }}=5 \cdot 10^{-18}, \quad R_{\text {small loops }}=0.02 \mu \mathrm{m}, \quad c_{\text {small loops }}=8.15 \cdot 10^{-10}$; dot line shows the results of calculation at $t_{\mathrm{am}}=0.75 \mu \mathrm{m}$, $k=0.033, R_{\text {big loops }}=20 \mu \mathrm{m}, c_{\text {big loops }}=5 \cdot 10^{-18}, c_{\text {big loops }}=5 \cdot 10^{-18}$, $R_{\text {small loops }}=0.02 \mu \mathrm{m}, c_{\text {small loops }}=4.172 \cdot 10^{-10}$; markers stand for the experimental data.

The solid lines in Figs. 1 and 2 demonstrate the results of calculation without account of 'small' defects. All the curves are practically identical with the experimental ones and slightly differ from each other. This indicates a weak sensitivity of the azimuthal dependences of TIIDD and weak selectivity of this sensitivity to structural parameters, at first, the concentration of 'small' RDDL and the parameter $k$ of the kinematically scattering sublayer of DSL. In addition, a non-negligible disagreement between the calculation and experimental data appears in all the considered cases of defect structures. This disagreement is different in all these cases and observed only at the minimum azimuthal angles. Therefore, the azimuthal dependences show the selective sensitivity to these structure parameters at minimum azimuthal angles. In what follows, we concentrate on the analysis of those of the considered features that could be used in the development of the physical basis of the phase-variation diagnostics. The principal idea of developed method is determination of experimental conditions that provide the predominant contribution from the selected type of defects to TIIDD. Obtaining the predominant contribution of selected type of defects is convenient when being combined with decreasing contribution to TIIDD from other types of defects. In other words, the contributions of these types (except the selected type) should be negligible. It enables to determine or refine the characteristics of the selected type of defects in single crystals at fixed values of other parameters of the experiment by elimination of the discrepancies between theory and experiment, similar to those already noted in Fig. 1.

The curves in Fig. 1 have a kink at azimuthal angles close to $95^{\circ}$, which is induced by increasing the contribution of diffuse scattering of X-rays. This contribution grows with increasing the azimuthal angle and is caused by the presence of 'large' RDDL (see also Fig. 7). This, by-turn, is caused by decreasing the width of the total reflection region (Darwin table) with increasing azimuthal angle. As a result, already for the angles close to $95^{\circ}$, the width of total reflection region is insufficient for overlapping of the peak of diffuse scattering and its reflection into the depth of the crystal. Thus, the appearance of kink is caused by the abovementioned dynamical coherent effects of multiple scattering of diffuse waves and, in particular, by the effect of total reflection and also the possible case of total reflection of all diffuse waves into the crystal. However, such almost complete overlap of the diffuse peak and, as a result, almost complete absence of contribution to the increase of intensities directly from the diffuse scattering by 'large' defects is provided gradually. This possibility can be used for further development of methods for phase-variation diagnostics. In particular, complete overlapping can significantly increase the efficiency of using the procedure developed below for elimination of the discrepancies between theory and experiment as well as for improving the sensitivity and informativeness of phase-variation diagnostics at minimum azimuthal angles, since at these angles the contribution from 'large' RDDL to the TIIDD disappears completely, reducing the number of unknown parameters of defects (see also Fig. 7).

Fig. 2 shows that for other reflection the normalized azimuthal dependences of TIIDD calculated without and with taking into account the presence of 'small' defects do not coincide with the experiment at all values of the azimuthal angles and significantly differ from each other. In addition, the azimuthal dependences of TIIDD calculated with account of 'small' defects are closer to the experiment. The explanation of lower experimental values of TIIDD, as compared with the results calculated 


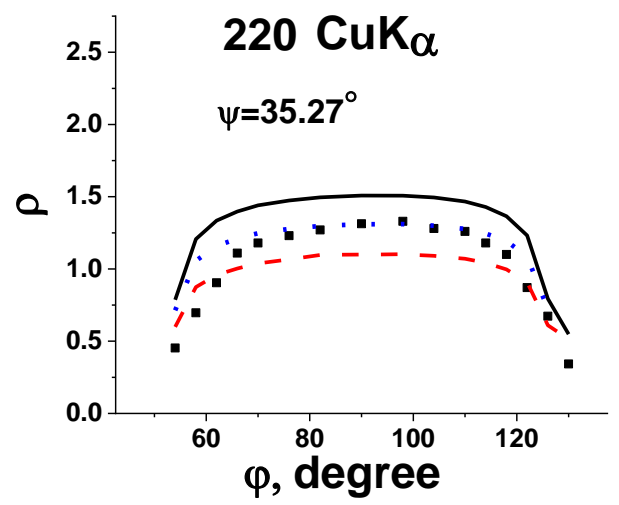

Fig. 3. The normalized azimuthal dependences of TIIDD $(\rho)$ for Bragg reflections (220), radiation $\mathrm{Cu} K_{\alpha}$. The solid line shows the results of calculation at $t_{\mathrm{am}}=0.75 \mu \mathrm{m}, \quad k=0.064$, $R_{\text {big loops }}=20 \mu \mathrm{m}, c_{\text {big loops }}=5 \cdot 10^{-18}$; dash line shows the results of calculation at $t_{\mathrm{am}}=0.75 \mu \mathrm{m}, k=0.004, R_{\mathrm{big} \text { loops }}=20 \mu \mathrm{m}$, $c_{\text {big loops }}=5 \cdot 10^{-18}, R_{\text {small loops }}=0.02 \mu \mathrm{m}, c_{\text {small loops }}=8.15 \cdot 10^{-10}$; dot line shows the results of calculation at $t_{\mathrm{am}}=0.75 \mu \mathrm{m}$, $k=0.033, \quad R_{\text {big loops }}=20 \mu \mathrm{m}, \quad c_{\text {big loops }}=5 \cdot 10^{-18}$, $R_{\text {small loops }}=0.02 \mu \mathrm{m}, c_{\text {small loops }}=4.172 \cdot 10^{-10} ;$ markers stand for the experimental data.

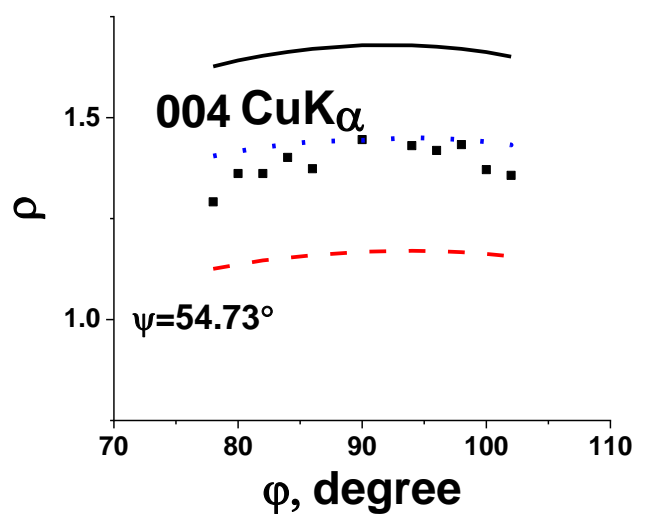

Fig. 4. The normalized azimuthal dependences of TIIDD $(\rho)$ for Bragg reflections (004), radiation $\mathrm{Cu} K_{\alpha}$. The solid line shows the results of calculation at $t_{\mathrm{am}}=0.75 \mu \mathrm{m}, k=0.064$, $R_{\text {big loops }}=20 \mu \mathrm{m}, c_{\text {big loops }}=5 \cdot 10^{-18}$; dash line shows the results of calculation at $t_{\mathrm{am}}=0.75 \mu \mathrm{m}, k=0.004, R_{\text {big loops }}=20 \mu \mathrm{m}$, $c_{\text {big loops }}=5 \cdot 10^{-18}, \quad R_{\text {small loops }}=0.02 \mu \mathrm{m}, \quad c_{\text {small loops }}=8.15 \cdot 10^{-10}$; dot line shows the results of calculation at $t_{\mathrm{am}}=0.75 \mu \mathrm{m}$, $k=0.033, \quad R_{\text {big loops }}=20 \mu \mathrm{m}, \quad c_{\text {big loops }}=5 \cdot 10^{-18}, \quad R_{\text {small loops }}=$ $0.02 \mu \mathrm{m}, \quad c_{\text {small loops }}=4.172 \cdot 10^{-10} ; \quad$ markers correspond to experimental data.

for (440) $M o K_{\alpha}$ reflection (on conditions that these values coincide for (220) reflection), was given in [2629 ] that the concentration of 'large' dislocation loops decreases into the depth of the sample. However, Fig. 2 shows that account of the presence of 'small' RDDL smoothes the concentration profile of 'large' RDDL. The similar correction of the concentration profile is also reasonable for 'small' dislocation loops and, if necessary, for other reflections.

In Figs 3 to 6 , the lines show the normalized azimuthal dependences of TIIDD at different diffraction conditions (different angles $\psi$ between the reflection plane

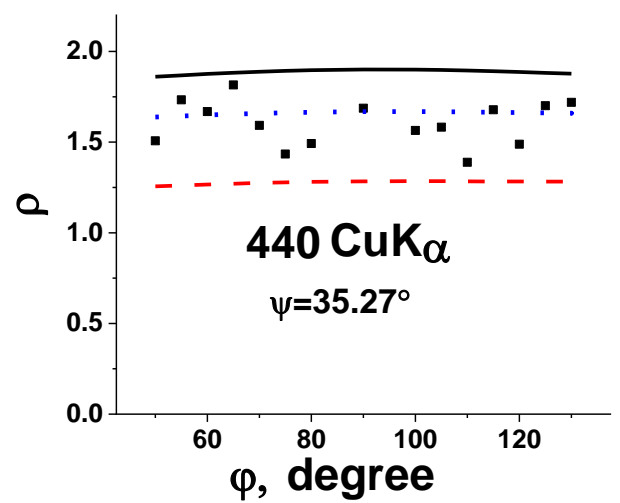

Fig. 5. The normalized azimuthal dependences of TIIDD $(\rho)$ for Bragg reflections (440), radiation $\mathrm{Cu} K_{\alpha}$. The solid line shows the results of calculation at $t_{\mathrm{am}}=0.75 \mu \mathrm{m}, \quad k=0.064$, $R_{\text {big loops }}=20 \mu \mathrm{m}, c_{\text {big loops }}=5 \cdot 10^{-18}$; dash line shows the results of calculation at $t_{\mathrm{am}}=0.75 \mu \mathrm{m}, \quad k=0.004, \quad R_{\text {big loops }}=20 \mu \mathrm{m}$, $c_{\text {big loops }}=5 \cdot 10^{-18}, R_{\text {small loops }}=0.02 \mu \mathrm{m}, c_{\text {small loops }}=8.15 \cdot 10^{-10} ;$ dot line shows the results of calculation at $t_{\mathrm{am}}=0.75 \mu \mathrm{m}, k=0.033$, $R_{\text {big loops }}=20 \mu \mathrm{m}, \quad c_{\text {big loops }}=5 \cdot 10^{-18}, \quad R_{\text {small loops }}=0.02 \mu \mathrm{m}$, $c_{\text {small loops }}=4.172 \cdot 10^{-10} ;$ markers are the experimental data.

and normal to the crystal surface and different energy radiations). The calculations also were carried out without and with account of the presence of 'small' RDDL as well as for the same values typical for parameters of defects and DSL as in Figs 1 and 2.

As can be seen in Figs 3 and 4, only dot lines $\left(t_{\mathrm{am}}=0.75 \mu \mathrm{m}, \quad k=0.033, \quad R_{\text {big loops }}=20 \mu \mathrm{m}, \quad c_{\text {big loops }}=\right.$ $5 \cdot 10^{-18}, \quad R_{\text {small loops }}=0.02 \mu \mathrm{m}, \quad c_{\text {small loops }}=4.172 \cdot 10^{-10}$ ) coincide with the experiment in all the considered cases, but not at all experimental points. Consequently, the parameters of single crystal defects determined in [2629] and partially corresponding to the solid lines in Figs 3 and 4 do not satisfy the new experimental data, which are more sensitive to DSL characteristics. The discrepancies of the calculations and experiment at the minimum and maximum azimuthal angles make it possible to further refine the defect parameters. The increase of the azimuthal dependences of TIIDD with increasing the azimuthal angles is absent for the cases in Figs 3 and 4 as opposed to Figs 1 and 2. This indicates the absence of contribution to TIIDD of the diffuse scattering from 'large' defects for all the azimuthal angles as a result of their total overlapping with the Darwin table. The possibility of such overlapping for minimal azimuthal angles was discussed when considering Fig. 1. In addition, as will be shown (Figs 7 and 9), the 'small' defects contribution is also small and reaches approximately $20 \%$ from the contribution of kinematically scattering sublayer of DSL opposite to the case in Fig. 1, where it is $100 \%$. This can simplify determination of DSL parameters in these diffraction cases with neglect of the RDDL contribution by fitting the calculated azimuthal dependences of TIIDD (dot lines) and experimental data, particularly at the minimum and maximum azimuthal angles. Thereafter, RDDL parameters should be determined by additional using the azimuthal dependences of TIIDD for other reflections 

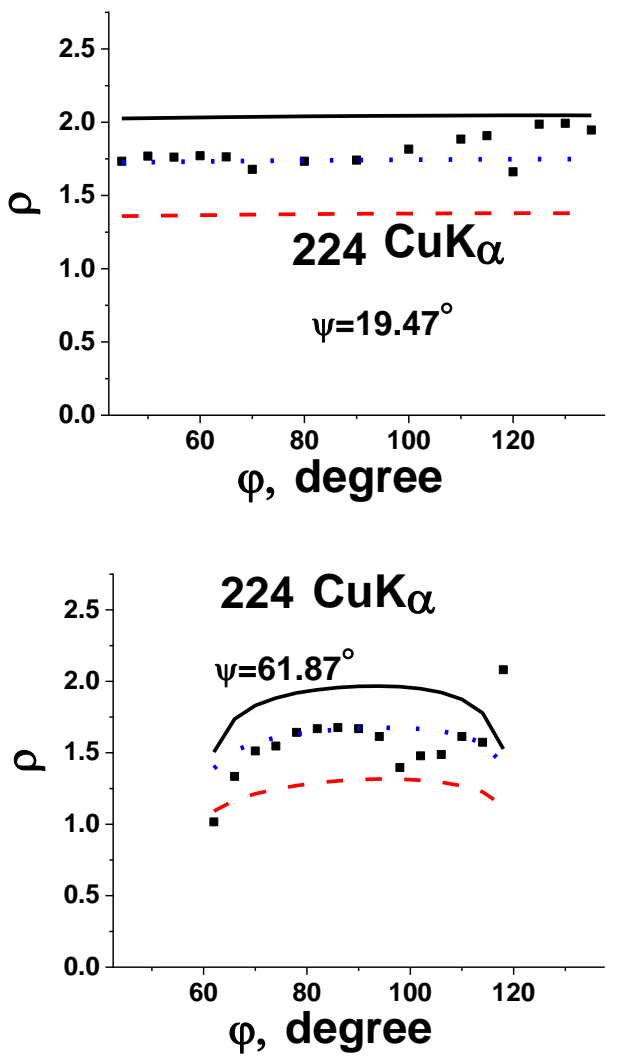

Fig. 6. The normalized azimuthal dependences of TIIDD $(\rho)$ for Bragg reflections (224), radiation $\mathrm{Cu} K_{\alpha}: \psi=19.47^{\circ}$ (a), $\psi=61.87^{\circ}(b)$. The solid line shows the results of calculation at $t_{\mathrm{am}}=0.75 \mu \mathrm{m}, k=0.064, R_{\text {big loops }}=20 \mu \mathrm{m}, \quad c_{\text {big loops }}=5 \cdot 10^{-18}$; dash line shows the results of calculation at $t_{\mathrm{am}}=0.75 \mu \mathrm{m}$, $k=0.004, \quad R_{\text {big loops }}=20 \mu \mathrm{m}, \quad c_{\text {big loops }}=5 \cdot 10^{-18}, \quad R_{\text {small loops }}=$ $0.02 \mu \mathrm{m}, c_{\text {small loops }}=8.15 \cdot 10^{-10}$; dot line shows the results of calculation at $t_{\mathrm{am}}=0.75 \mu \mathrm{m}, k=0.033, \quad R_{\text {big loops }}=20 \mu \mathrm{m}$, $c_{\text {big loops }}=5 \cdot 10^{-18}, R_{\text {small loops }}=0.02 \mu \mathrm{m}, c_{\text {small loops }}=4.172 \cdot 10^{-10}$; markers are the experimental data.

under the assumption that the DSL parameters are already obtained. Thus, it is reasonable to determine the RDDL parameters from experimental results, which are shown in Fig. 1. At first, it is necessary to determine the parameters of 'large' loops by using the azimuthal dependences of TIIDD at the azimuthal angles as higher as possible than $90^{\circ}$ and then to determine the 'small' loops parameters at the angles as lower as possible than $90^{\circ}$ under the assumption that the DSL parameters and 'large' defects parameters are already known. The azimuthal dependences of TIIDD for other reflections can be additionally used for subsequent increasing the diagnostics sensitivity and informativeness, in particular for determining the depth profiles of RDDL.

Figs 5 and 6 demonstrate the azimuthal dependences of TIIDD also obtained using radiation $\mathrm{Cu} K_{\alpha}$, but for other reflections as compared with Figs 3 and 4 and at various angles $\psi$.

Figs 1 to 6 show that azimuthal dependences of TIIDD calculated at $t_{\mathrm{am}}=0.75 \mu \mathrm{m}, \quad k=0.033$, $R_{\text {big loops }}=20 \mu \mathrm{m}, c_{\text {big loops }}=5 \cdot 10^{-18}, R_{\text {small loops }}=0.02 \mu \mathrm{m}$,

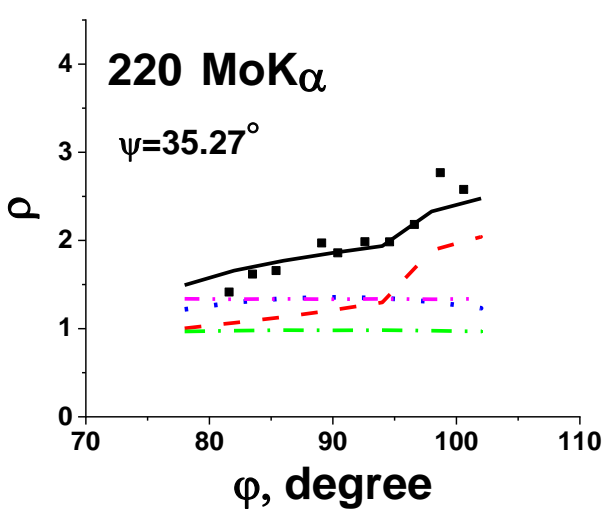

Fig. 7. The normalized azimuthal dependences of TIIDD $(\rho)$ for Bragg reflections (220), radiation $\operatorname{Mo} K_{\alpha}$. The solid line shows the results of calculation at $t_{\mathrm{am}}=0.75 \mu \mathrm{m}, k=0.033$, $R_{\text {big loops }}=20 \mu \mathrm{m}, \quad c_{\text {big loops }}=5 \cdot 10^{-18}, \quad R_{\text {small loops }}=0.02 \mu \mathrm{m}$, $c_{\text {small loops }}=4.172 \cdot 10^{-10} ;$ dash line shows the results of calculation at $t_{\mathrm{am}}=0, k=0, R_{\text {big loops }}=20 \mu \mathrm{m}, c_{\text {big loops }}=5 \cdot 10^{-18}$, $c_{\text {small loops }}=0$; dot line shows the results of calculation at $t_{\mathrm{am}}=0$, $k=0, R_{\text {small loops }}=0.02 \mu \mathrm{m}, c_{\text {small loops }}=4.172 \cdot 10^{-10}, c_{\text {big loops }}=0$; dash-dot line shows the results of calculation at $t_{\mathrm{am}}=0.75 \mu \mathrm{m}$, $k=0, c_{\text {big loops }}=0, c_{\text {small loops }}=0$; dash-double dot line shows the results of calculation at $t_{\mathrm{am}}=0, k=0.033, c_{\text {big loops }}=0$, $c_{\text {small loops }}=0$; markers correspond for experimental data.

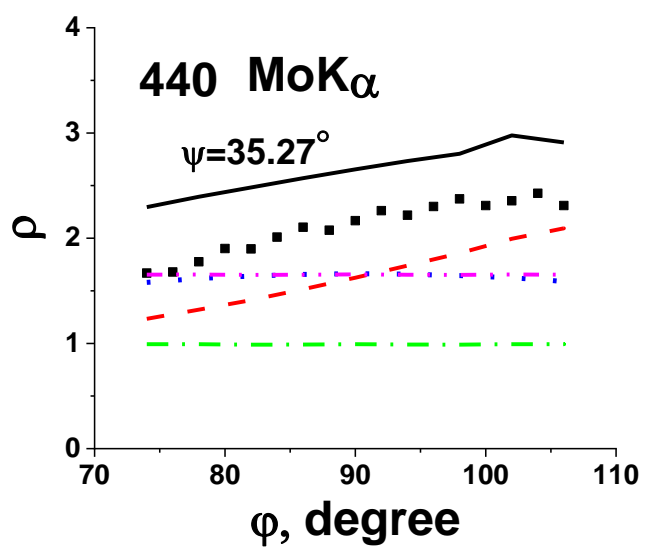

Fig. 8. The normalized azimuthal dependences of TIIDD $(\rho)$ for Bragg reflections (440), radiation $\operatorname{Mo} K_{\alpha}$. The solid line shows the results of calculation at $t_{\mathrm{am}}=0.75 \mu \mathrm{m}, \quad k=0.033$, $R_{\text {big loops }}=20 \mu \mathrm{m}, \quad c_{\text {big loops }}=5 \cdot 10^{-18}, \quad R_{\text {small loops }}=0.02 \mu \mathrm{m}$, $c_{\text {small loops }}=4.172 \cdot 10^{-10} ;$ dash line shows the results of calculation at $t_{\mathrm{am}}=0, k=0, R_{\text {big loops }}=20 \mu \mathrm{m}, c_{\text {big loops }}=5 \cdot 10^{-18}$, $c_{\text {small loops }}=0$; dot line shows the results of calculation at $t_{\mathrm{am}}=0$, $k=0, R_{\text {small loops }}=0.02 \mu \mathrm{m}, c_{\text {small loops }}=4.172 \cdot 10^{-10}, c_{\text {big loops }}=0$; dash-dot line shows the results of calculation at $t_{\mathrm{am}}=0.75 \mu \mathrm{m}$, $k=0, c_{\text {big loops }}=0, c_{\text {small loops }}=0$; dash-double dot line shows the results of calculation at $t_{\mathrm{am}}=0, k=0.033, c_{\text {big loops }}=0$, $c_{\text {small loops }}=0$; markers stand for the experimental data.

$c_{\text {small loops }}=4.172 \cdot 10^{-10}$ have the best coincidence with the experiment. This confirms reasonableness of the fulfilled structure diagnostics. However, the proposed development in phase-variation diagnostics should make it possible to increase its sensitivity and informativeness when determining the parameters of other types of defects. 


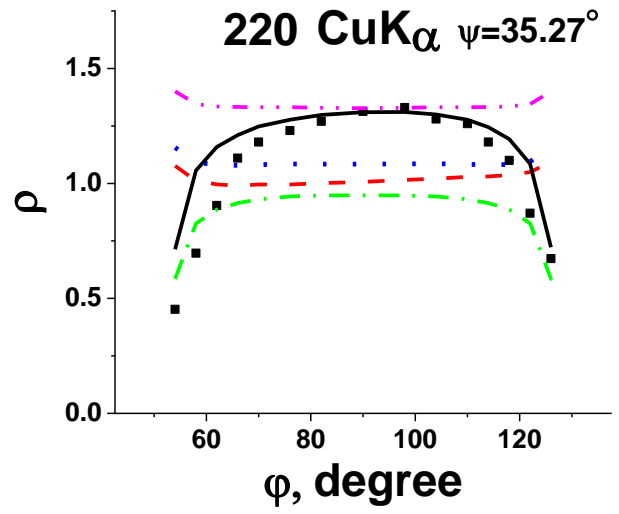

Fig. 9. The normalized azimuthal dependences of TIIDD ( $\rho$ ) for Bragg reflections (220), radiation $\mathrm{Cu} K_{\alpha}$. The solid line shows the results of calculation at $t_{\mathrm{am}}=0.75 \mu \mathrm{m}, k=0.033$, $R_{\text {big loops }}=20 \mu \mathrm{m}, \quad c_{\text {big loops }}=5 \cdot 10^{-18}, \quad R_{\text {small loops }}=0.02 \mu \mathrm{m}$, $c_{\text {small loops }}=4.172 \cdot 10^{-10}$; dash line shows the results of calculation at $t_{\mathrm{am}}=0, k=0, R_{\text {big loops }}=20 \mu \mathrm{m}, c_{\text {big loops }}=5 \cdot 10^{-18}$, $c_{\text {small loops }}=0$; dot line shows the results of calculation at $t_{\mathrm{am}}=0, \quad k=0, \quad R_{\text {small loops }}=0.02 \mu \mathrm{m}, \quad c_{\text {small loops }}=4.172 \cdot 10^{-10}$, $c_{\text {big loops }}=0$; dash-dot line shows the results of calculation at $t_{\text {am }}=0.75 \mu \mathrm{m}, k=0, c_{\text {big loops }}=0, c_{\text {small loops }}=0$; dash-double dot line shows the results of calculation at $t_{\mathrm{am}}=0, k=0.033$, $c_{\text {big loops }}=0, c_{\text {small loops }}=0$; markers are the experimental data.

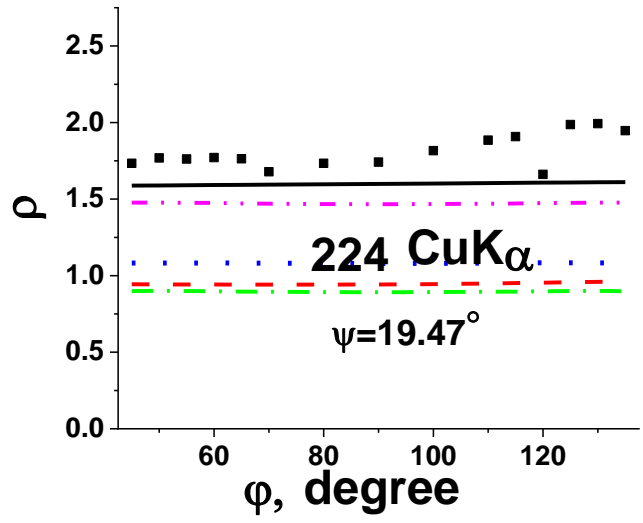

Fig. 11. The normalized azimuthal dependences of TIIDD $(\rho)$ for Bragg reflections (224), radiation $\mathrm{Cu} K_{\alpha}, \psi=19.47^{\circ}$. The solid line shows the results of calculation at $t_{\mathrm{am}}=0.75 \mu \mathrm{m}$, $k=0.033, \quad R_{\text {big loops }}=20 \mu \mathrm{m}, \quad c_{\text {big loops }}=5 \cdot 10^{-18}, \quad R_{\text {small loops }}=$ $0.02 \mu \mathrm{m}, c_{\text {small loops }}=4.172 \cdot 10^{-10}$; dash line shows the results of calculation at $t_{\mathrm{am}}=0, k=0, R_{\text {big loops }}=20 \mu \mathrm{m}, c_{\text {big loops }}=$ $5 \cdot 10^{-18}, c_{\text {small loops }}=0$; dot line shows the results of calculation at $t_{\mathrm{am}}=0, k=0, R_{\text {small loops }}=0.02 \mu \mathrm{m}, c_{\text {small loops }}=4.172 \cdot 10^{-10}$, $c_{\text {big loops }}=0$; dash-dot line shows the results of calculation at $t_{\mathrm{am}}=0.75 \mu \mathrm{m}, k=0, c_{\text {big loops }}=0, c_{\text {small loops }}=0$; dash-double dot line shows the results of calculation at $t_{\mathrm{am}}=0, k=0.033$, $c_{\text {big loops }}=0, c_{\text {small loops }}=0$; markers stand for the experimental data.

Figs 7 to 13 demonstrate the normalized azimuthal dependences of TIIDD calculated on the assumption that the crystal contains only 'large' RDDL, or only 'small' RDDL, or only DSL with the parameters: $t_{\mathrm{am}}=0.75 \mu \mathrm{m}$, $k=0.033, \quad R_{\text {big loops }}=20 \mu \mathrm{m}, \quad c_{\text {big loops }}=5 \cdot 10^{-18}$, $R_{\text {small loops }}=0.02 \mu \mathrm{m}, \quad c_{\text {small loops }}=4.172 \cdot 10^{-10}$. The plots show specific contributions to the normalized azimuthal dependences of TIIDD from every type of these defects.

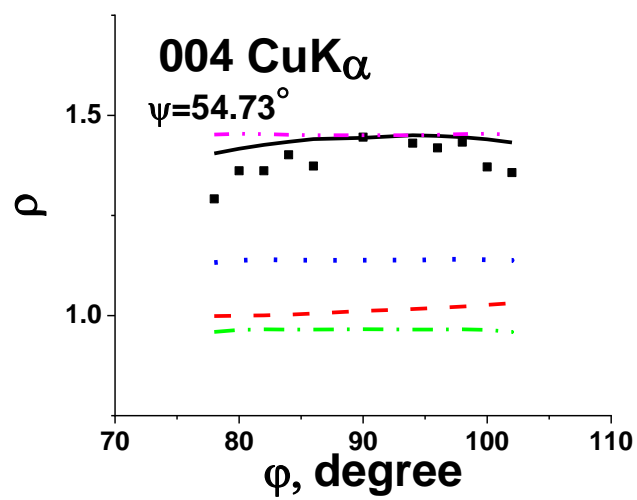

Fig. 10. The normalized azimuthal dependences of TIIDD $(\rho)$ for Bragg reflections (004), radiation $\mathrm{Cu} K_{\alpha}$. The solid line shows the results of calculation at $t_{\mathrm{am}}=0.75 \mu \mathrm{m}, k=0.033$, $R_{\text {big loops }}=20 \mu \mathrm{m}, \quad c_{\text {big loops }}=5 \cdot 10^{-18}, \quad R_{\text {small loops }}=0.02 \mu \mathrm{m}$, $c_{\text {small loops }}=4.172 \cdot 10^{-10}$; dash line shows the results of calculation at $t_{\mathrm{am}}=0, k=0, R_{\text {big loops }}=20 \mu \mathrm{m}, c_{\text {big loops }}=5 \cdot 10^{-18}$, $c_{\text {small loops }}=0$; dot line shows the results of calculation at $t_{\mathrm{am}}=0, k=0, \quad R_{\text {small loops }}=0.02 \mu \mathrm{m}, \quad c_{\text {small loops }}=4.172 \cdot 10^{-10}$, $c_{\text {big loops }}=0$; dash-dot line shows the results of calculation at $t_{\mathrm{am}}=0.75 \mu \mathrm{m}, k=0, c_{\text {big loops }}=0, c_{\text {small loops }}=0$; dash-double dot line shows the results of calculation at $t_{\mathrm{am}}=0, k=0.033$, $c_{\text {big loops }}=0, c_{\text {small loops }}=0$; markers show the experimental data.

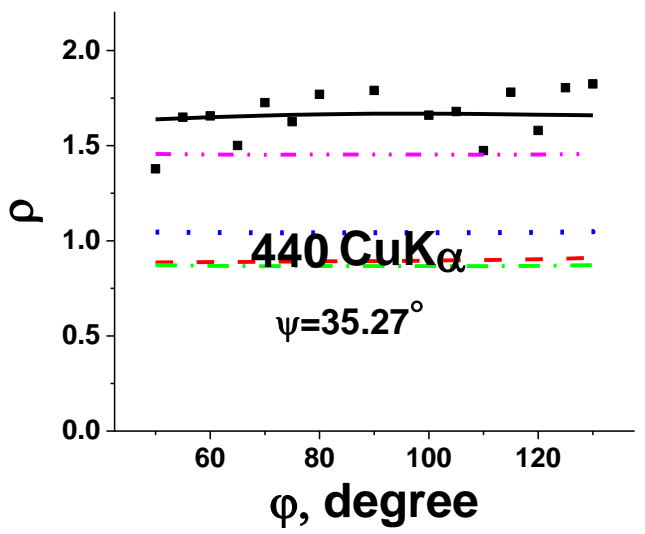

Fig. 12. The normalized azimuthal dependences of TIIDD $(\rho)$ for Bragg reflections (440), radiation $\mathrm{Cu} K_{\alpha}$. The solid line shows the results of calculation at $t_{\mathrm{am}}=0.75 \mu \mathrm{m}, k=0.033$, $R_{\text {big loops }}=20 \mu \mathrm{m}, \quad c_{\text {big loops }}=5 \cdot 10^{-18}, \quad R_{\text {small loops }}=0.02 \mu \mathrm{m}$, $c_{\text {small loops }}=4.172 \cdot 10^{-10} ;$ dash line shows the results of calculation at $t_{\mathrm{am}}=0, k=0, R_{\text {big loops }}=20 \mu \mathrm{m}, c_{\text {big loops }}=5 \cdot 10^{-18}$, $c_{\text {small loops }}=0$; dot line shows the results of calculation at $t_{\mathrm{am}}=0, k=0, \quad R_{\text {small loops }}=0.02 \mu \mathrm{m}, \quad c_{\text {small loops }}=4.172 \cdot 10^{-10}$, $c_{\text {big loops }}=0$; dash-dot line shows the results of calculation at $t_{\mathrm{am}}=0.75 \mu \mathrm{m}, k=0, c_{\text {big loops }}=0, c_{\text {small loops }}=0$; dash-double dot line shows the results of calculation at $t_{\mathrm{am}}=0, k=0.033$, $c_{\text {big loops }}=0, \quad c_{\text {small loops }}=0 ; \quad$ markers correspond to the experimental data.

Figs 7 and 8 show that DSL and 'small' RDDL are the predominant types of defects at $\varphi \leq 90^{\circ}$ and radiation $\mathrm{Mo} K_{\alpha}$, as well as 'large' RDDL are the predominant types of defects at $\varphi>90^{\circ}$ and radiation $\operatorname{MoK}_{\alpha}$ (see also comments to Figs 1-4). As a result, using the additional experimental conditions can help to determine the depth distribution profiles of RDDL. 
It should be noted that in Fig. 9 the extinction length $\Lambda\left(\varphi=90^{\circ}\right)=5.91 \mu \mathrm{m}$ in the presence of 'large' and 'small' defects and $\Lambda\left(\varphi=90^{\circ}\right)=5.63 \mu \mathrm{m}$ in the absence of defects.

It is noteworthy that in Fig. 10 the extinction length $\Lambda\left(\varphi=90^{\circ}\right)=7.32 \mu \mathrm{m}$ in the presence of 'large' and 'small' defects and $\Lambda\left(\varphi=90^{\circ}\right)=6.75 \mu \mathrm{m}$ in the absence of defects.

It is worth to note that in Fig. 11 the extinction length $\Lambda\left(\varphi=90^{\circ}\right)=17.24 \mu \mathrm{m}$ in the presence of 'large' and 'small' defects and $\Lambda\left(\varphi=90^{\circ}\right)=15.45 \mu \mathrm{m}$ in the absence of defects.

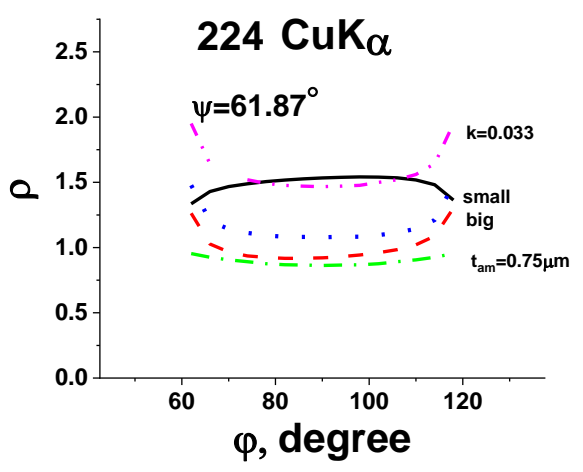

Fig. 13. The normalized azimuthal dependences of TIIDD $(\rho)$ for Bragg reflections (224), radiation $\mathrm{Cu} K_{\alpha}, \psi=61.87^{\circ}$. The solid line shows the results of calculation at $t_{\mathrm{am}}=0.75 \mu \mathrm{m}$, $k=0.033, \quad R_{\text {big loops }}=20 \mu \mathrm{m}, \quad c_{\text {big loops }}=5 \cdot 10^{-18}, \quad R_{\text {small loops }}=$ $0.02 \mu \mathrm{m}, c_{\text {small loops }}=4.172 \cdot 10^{-10}$; dash line shows the results of calculation at $t_{\mathrm{am}}=0, k=0, R_{\text {big loops }}=20 \mu \mathrm{m}, c_{\text {big loops }}=5 \cdot 10^{-18}$, $c_{\text {small loops }}=0$; dot line shows the results of calculation at $t_{\mathrm{am}}=0$, $k=0, R_{\text {small loops }}=0.02 \mu \mathrm{m}, c_{\text {small loops }}=4.172 \cdot 10^{-10}, c_{\text {big loops }}=0$; dash-dot line shows the results of calculation at $t_{\mathrm{am}}=0.75 \mu \mathrm{m}$, $k=0, c_{\text {big loops }}=0, c_{\text {small loops }}=0$; dash-double dot line shows the results of calculation at $t_{\mathrm{am}}=0, k=0.033, \quad c_{\text {big loops }}=0$, $c_{\text {small loops }}=0$; markers stand for the experimental data.

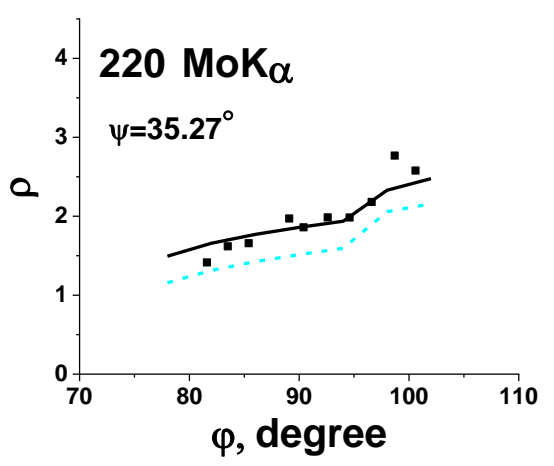

Fig. 14. The normalized azimuthal dependences of TIIDD ( $\rho)$ for Bragg reflections (220), radiation $\operatorname{Mo} K_{\alpha}$. The solid line shows the results of calculation at $t_{\mathrm{am}}=0.75 \mu \mathrm{m}, k=0.033$, $R_{\text {big loops }}=20 \mu \mathrm{m}, \quad c_{\text {big loops }}=5 \cdot 10^{-18}, \quad R_{\text {small loops }}=0.02 \mu \mathrm{m}$, $c_{\text {small loops }}=4.172 \cdot 10^{-10} ;$ dash line shows the results of calculation at $t_{\mathrm{am}}=0.75 \mu \mathrm{m}, \quad k=0, \quad R_{\text {big loops }}=20 \mu \mathrm{m}$, $c_{\text {big loops }}=5 \cdot 10^{-18}, R_{\text {small loops }}=0.02 \mu \mathrm{m}, c_{\text {small loops }}=4.172 \cdot 10^{-10}$; markers show the experimental data.

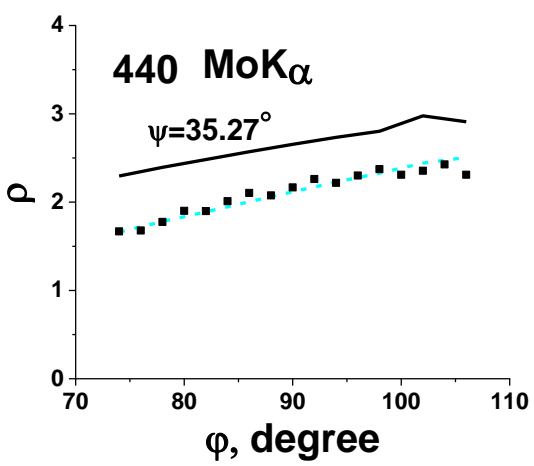

Fig. 15. The normalized azimuthal dependences of TIIDD $(\rho)$ for Bragg reflections (440), radiation $\operatorname{Mo} K_{\alpha}$. The solid line shows the results of calculation at $t_{\mathrm{am}}=0.75 \mu \mathrm{m}, k=0.033$, $R_{\text {big loops }}=20 \mu \mathrm{m}, \quad c_{\text {big loops }}=5 \cdot 10^{-18}, \quad R_{\text {small loops }}=0.02 \mu \mathrm{m}$, $c_{\text {small loops }}=4.172 \cdot 10^{-10}$; dash line shows the results of calculation at $t_{\mathrm{am}}=0.75 \mu \mathrm{m}, \quad k=0, \quad R_{\text {big loops }}=20 \mu \mathrm{m}$, $c_{\text {big loops }}=5 \cdot 10^{-18}, R_{\text {small loops }}=0.02 \mu \mathrm{m}, c_{\text {small loops }}=4.172 \cdot 10^{-10}$; markers correspond to the experimental data.

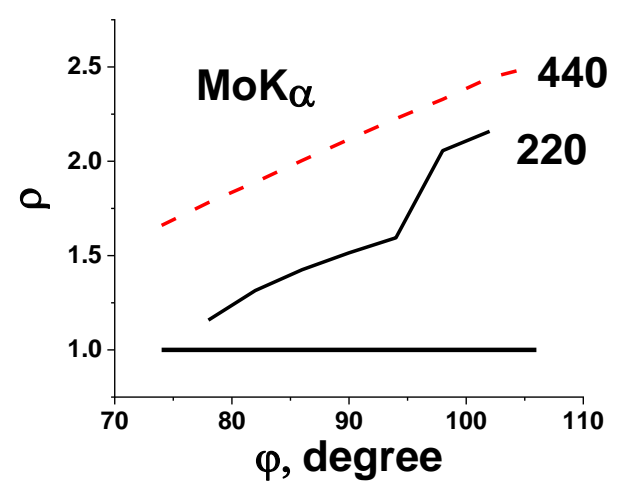

Fig. 16. The normalized azimuthal dependences of TIIDD $(\rho)$ for Bragg reflections (220) and (440), radiation $M o K_{\alpha}$. $t_{\mathrm{am}}=0.75 \mu \mathrm{m}, \quad k=0, \quad R_{\text {big loops }}=20 \mu \mathrm{m}, \quad c_{\text {big loops }}=5 \cdot 10^{-18}$, $R_{\text {small loops }}=0.02 \mu \mathrm{m}, c_{\text {small loops }}=4.172 \cdot 10^{-10}$, the bold solid line shows the results for the perfect crystal.

Note that in Fig. 12 the extinction length $\Lambda\left(\varphi=90^{\circ}\right)=20.24 \mu \mathrm{m}$ in the presence of 'large' and 'small' defects and $\Lambda\left(\varphi=90^{\circ}\right)=17.67 \mu \mathrm{m}$ in the absence of defects.

It is important to note that in Fig. 13 the extinction length $\Lambda\left(\varphi=90^{\circ}\right)=8.55 \mu \mathrm{m}$ in the presence of 'large' and 'small' defects and $\Lambda\left(\varphi=90^{\circ}\right)=7.72 \mu \mathrm{m}$ in the absence of defects.

Figs 9 to 13 show that DSL is the predominant type of defects at radiation $\mathrm{Cu} K_{\alpha}$. In addition, the significant sensitivity to 'small' RDDL appears in some diffraction cases.

Figs 14 to 16 additionally illustrate the sensitivity of the azimuthal dependences of TIIDD to 'large' and 'small' RDDL in different diffraction conditions.

Fig. 14 demonstrates that TIIDD calculated without account of the contribution of kinematically scattering DSL sublayer is only less by $13 \%$ than the experimental TIIDD. It is nearly $25 \%$ corresponding to the integrated intensity of dynamical diffraction for perfect crystal. 
The experimental TIIDD differ from the corresponding integrated intensity of dynamical diffraction for perfect crystal by $50 \ldots 150 \%$, i.e. RDDL are the dominant type of defects (see also comments to Figs 1 and 7).

Fig. 15 shows that TIIDD calculated without account of the contribution of kinematically scattering sublayer of DSL are in good agreement with the experimental data. The reason is the concentration of 'large' RDDL can be less than the calculated values due to the concentration decrease with the sample depth.

The results presented in Figs 14 and 15 enable to demonstrate the significant contribution in TIIDD from 'large' and 'small' RDDL.

Fig. 16 more clearly demonstrates the contribution directly from RDDL (in the absence of the contribution from DSL). Fig. 16 shows that the difference of TIIDD in the single crystal with RDDL from the integrated intensity of dynamical diffraction of the perfect crystal can be higher than $120 \ldots 170 \%$.

\section{Discussions}

Thus, among the most important new physical features of the dynamical diffraction in single crystals with defects determined in this article and formulated on their basis proposals to improve efficiency of application of the phase-variation principles for increasing the sensitivity and informativeness of the diagnostics it is proposed to use the following features:

1) The new dynamical effect is demonstrated in the case of dynamical Bragg diffraction. This effect appears as the possibility to practically entirely suppress contribution of the diffuse scattering from 'large' defects to TIIDD by targeted choice of experimental conditions. The suppression can occur, as an example, when the dislocation loops are sufficiently 'large' and the halfwidth of the peak of angular distribution of diffuse scattering inversely proportional to their radius is sufficiently small. It can bring to the total overlapping the diffuse scattering peak by the range of the dynamical total reflection effect. Therewith the total reflection range (the Darwin table width) should be significant. The width of Darwin table is inversely proportional to the extinction length, which for implementation of the mentioned effect should be chosen sufficiently small (sufficiently less than the loops radius). It can be realized, for instance, by choice of the X-ray sources with small radiation energy and reflections with small Miller indices. For this goal, in the paper $\operatorname{Mo} K_{\alpha}$ radiation and the reflection (220) at the minimum azimuthal angles or $\mathrm{Cu} K_{\alpha}$ radiation and the reflection (220) are mainly used. For chosen reflections, the extinction lengths are approximately three times less than the 'large' RDDL radius, which allows experimental verification of the effect. It provides the possibility to use the discovered effect for increasing the sensitivity and informativeness of the phase-variation diagnostics by the requirements substitution in the next way. The previous way required to provide the predominant contribution for every type of defects that are present in the crystal into the measured intensity. The new method requires to practically provide the only contribution from one chosen type of defects and to reduce to zero the contributions from other types of defects. Therewith, if the single crystal contains, beside 'large' RDDL, another type of defects (for example, 'small' defects with a high concentration), then the characteristics of this type of defects can be determined first by using the proposed method (by complete suppression of diffuse scattering from 'large' RDDL). Further, using these determined characteristics and the measurements of the azimuthal dependences of TIIDD under other experimental conditions (for example, radiation $\mathrm{Mo} K_{\alpha}$ and the azimuthal angles higher than $90^{\circ}$ ) the 'large' RDDL characteristics can be determined. It becomes possible when both types of defects give contribution, and the latter of 'large' RDDL additionally enhanced by the Bormann effect becomes determinative. For the cases of only two types of defects, the new method enables to completely determine parameters of defect structure.

2) However, characterization of the single crystal with 'large' and 'small' RDDL and with two sublayers of DSL requires additional generalizations of the new approach proposed. It is necessary to exclude the diffuse scattering from 'small' defects, which is impossible by using the total reflection effect. The effect of anomalous growth of the diffuse scattering contribution in TIIDD, which increases with the growth of ratio of extinction length to the absorption one, can be used for this aim. The effect of anomalous growth already proposed in this article for the suppression of the contribution of the diffuse scattering from the 'large' RDDL provides decreasing the absorption and extinction lengths ratio and consequently almost complete suppression of the diffuse scattering contribution from 'small' RDDL. As a result, the characteristics of DSL can be determined from these experimental data. Therewith, the contributions of RDDL are negligibly small.

However, DSL consists of two layers, i.e., there are two types of defects. The selectivity of sensitivities of the azimuthal dependences of TIIDD to parameters of sublayers as well as changes in this selectivity with variations of scattering vectors and the azimuthal angles are significantly different for these sublayers. It can be used to develop new, more efficient methods for the phasevariation diagnostics of these systems. However, the solution of this problem is beyond the scope of this article.

\section{Conclusions}

Thus, the presented results allow us to conclude that the sensitivity and informativeness of nondestructive structural phase-variation diagnostics of multiparametrical systems can be improved by both purposefully expanding the experimental conditions (in this article molybdenum and copper radiation sources) and by keeping the order of determining the parameters inherent to each type of defects. Respective calculation should be started with defects, for which it is possible to provide their predominant contribution to the azimuthal dependences of TIIDD. 
The presented calculations have been carried out in the order proposed in [26-29]. However, even using the only additional copper source of radiation enables to significantly increase the sensitivity and informativeness of diagnostics and to determine the parameters of defects: $t_{\mathrm{am}}=0.75 \mu \mathrm{m}, \quad k=0.033, \quad R_{\text {big loops }}=20 \mu \mathrm{m}, \quad c_{\text {big loops }}=$ $5 \cdot 10^{-18}, R_{\text {small loops }}=0.02 \mu \mathrm{m}, c_{\text {small loops }}=4.172 \cdot 10^{-10}$. These values are considerably different from the parameters calculated in [26-29] $\left(R_{\text {big loops }}=20 \mu \mathrm{m}, c_{\text {big loops }}=2.8 \cdot 10^{-19}\right.$, $\left.t_{\mathrm{am}}=0.1 \mu \mathrm{m}, k=0.25\right)$. As can be seen from these results, it was possible to improve by an order of magnitude the accuracy of determining the DSL parameters and additionally determine the parameters of 'small' RDDL.

\section{References}

1. Krivoglaz M.A. Diffraction of X-Rays and Thermal Neutrons in Imperfect Crystals. Springer, 1992.

2. Schmidbauer M. X-ray Diffuse Scattering from SelfOrganized Mesoscopic Semiconductor Structures. Berlin, Heidelberg: Springer, 2010.

https://doi.org/10.1002/chin.200212280.

3. Benediktovich A., Feranchuk I., and Ulyanenkov A. Theoretical Concepts of X-Ray Nanoscale Analysis: Theory and Applications. Berlin: Springer Science \& Business Media, 2013. https://doi.org/10.1007/978-3-642-38177-5.

4. Schmidbauer M., Schäfer P., Besedin S. et al. A novel multi-detection technique for three-dimensional reciprocal-space mapping in grazing-incidence X-ray diffraction. J. Synchrotron Rad. 2008. 15. P. 549-557. https://doi.org/10.1107/S0909049508023856.

5. Cornelius T.W., Davydok A., Jacques V.L.R. et al. In situ three-dimensional reciprocal-space mapping during mechanical deformation. J. Synchrotron Rad. 2012. 19. P. 688-694. https://doi.org/10.1107/S0909049512023758.

6. Lazarev S., Barchuk M., Bauer S. et al. Study of threading dislocation density reduction in $\mathrm{AlGaN}$ epilayers by Monte Carlo simulation of highresolution reciprocal-space maps of a two-layer system. J. Appl. Cryst. 2013. 46. P. 120-127. https://doi.org/10.1107/S0021889812043051.

7. Shabalin A.G., Meijer J.-M., Dronyak R. et al. Revealing three-dimensional structure of an individual colloidal crystal grain by coherent X-Ray diffractive imaging. Phys. Rev. Lett. 2016. 117. P. 138002. https://doi.org/10.1103/PhysRevLett.117.138002.

8. Suturin S.M., Fedorov V.V., Korovin A.M. et al. Epitaxial Ni nanoparticles on $\mathrm{CaF}_{2}(001)$, (110) and (111) surfaces studied by three-dimensional RHEED, GIXD and GISAXS reciprocal-space mapping techniques. J. Appl. Cryst. 2017. 50. P. 830-839. https://doi.org/10.1107/S160057671700512X.

9. Chukhovskii F.N., Konarev P.V., and Volkov V.V. Towards a solution of the inverse X-ray diffraction tomography challenge: theory and iterative algorithm for recovering the 3D displacement field function of Coulomb-type point defects in a crystal. Acta Crystallogr. A. 2020. 76. P. 163-167. https://doi.org/10.1107/S2053273320000145.

10. Lizunov V.V., Molodkin V.B., Lizunova S.V. et al. The phenomenon of intensification (by several orders of magnitude) defects' manifestation in the multiple-scattering pattern and its dispersive nature. Metallofiz. Noveishie Tekhnol. 2014. 36, No 7. P. 857 (in Russian).

11. Skapa L.N., Lizunov V.V., Molodkin V.B. et al. Dispersion effects of interconnection of the scattering pattern dependences on different diffraction conditions and huge intensification of these dependences and their structure sensitivity and informativeness. Metallofiz. Noveishie Tekhnol. 2015. 37, No 11. P. 1567 (in Russian).

12. Lizunov V.V., Zabolotnyy I.M., Vasylyk Ya.V. et al. Integrated diffractometry: Achieved progress and new performance capabilities. Usp. Fiz. Met. 2019. 20, No 1. P. 75.

https://doi.org/10.15407/ufm.20.01.075.

13. Stevenson A.W. X-ray integrated intensities from semiconductor substrates and epitaxic layers - a comparison of kinematical and dynamical theories with experiment. Acta Crystallogr. A. 1993. 49. P. 174-183. https://doi.org/10.1107/S0108767392007438.

14. Baryakhtar V.G., Kovalchuk M.V., Litvinov Yu.M. et al. Total integrated intensity of Bragg-diffracted synchrotron radiation for crystals with defects. Nucl. Instr. Meth. Phys. Res. A. 1991. 308. P. 291. https://doi.org/10.1016/0168-9002(91)90650-F.

15. Nemoshkalenko V.V., Molodkin V.B., Kislovski E.N. et al. Metallofiz. Noveishie Tekhnol. 1994. 16. P. 48 (in Russian).

16. Baryakhtar V.G., Nemoshkalenko V.V., Molodkin V.B. et al. Metallofiz. Noveishie Tekhnol. 1994. 16. P. 21 (in Russian).

17. Lizunov V. V., Molodkin V.B., Olikhovskii S. I. et al. New possibilities of integral dynamic diffractometry of crystal imperfections. Metallofiz. Nov. Tekhnol. 2015. 37. P. 265-279 (in Russian).

18. Kato N. Statistical dynamical theory of crystal diffraction. I. General formulation. Acta Crystallogr. A. 1980. 36. P. 763-769. https://doi.org/10.1107/S0567739480001544.

19. Al Haddad M., and Becker P.J. On the statistical dynamical theory of diffraction: application to silicon. Acta Crystallogr. A. 1988. 44. P. 262-270. https://doi.org/10.1107/S0108767387011681.

20. Becker P. and Al Haddad M. Diffraction by a randomly distorted crystal. II. General theory. Acta Crystallogr. A. 1992. 48. P. 121-134. https://doi.org/10.1107/S0108767391009376.

21. Guigay J.P. and Chukhovskii F.N. Reformulation of the dynamical theory of coherent wave propagation by randomly distorted crystals. Acta Crystallogr. A. 1992. 48. P. 819-826. https://doi.org/10.1107/S0108767392003830.

22. Chukhovskii F.N. and Guigay J.P. Towards a rigorous treatment of the wave-field propagation according to the statistical theory of dynamical diffraction. J. Phys. D: Appl. Phys. A. 1993. 26. P. 53. https://doi.org/10.1088/0022-3727/26/4A/012.

23. Dederichs P.H. Diffuse scattering from defect clusters near Bragg reflections. Phys. Rev. B. 1971. 4. P. 1041. https://doi.org/10.1103/PhysRevB.4.1041. 
24. Thomas J.E., Baldwin T.O., and Dederichs P.H. Diffuse X-ray scattering in fast-neutron-irradiated copper crystals. Phys. Rev. B. 1971. 3. P. 1167. https://doi.org/10.1103/PhysRevB.3.1167.

25. Molodkin V.B., Olikhovskii S.I., Osinovskii M.E. et al. The integrated intensities of the Lauediffracted X-rays for monocrystals containing macroscopically homogeneously distributed defects. phys. status solidi (a). 1985. 87. P. 597. https://doi.org/10.1002/pssa.2210870223.

26. Molodkin V.B., Dmitriev S.V., Pervak E.V. et al. The effect of asymmetry of the azimuthal dependence of the integral intensity of Bragg diffraction in single crystals with defects. Metallofiz. Noveishie Tekhnol. 2006. 28, No 8. P. 1077-1084 (in Russian).

27. Molodkin V.B., Nizkova A.I., Vasylyk Ya.V. et al. Principles of X-ray diffractometry of single-crystal non-uniformly distributed microdefects compared with extinction length. Metallofiz. Noveishie Tekhnol. 2012. 34, No 5. P. 705-711 (in Russian).

28. Molodkin V.B., Nizkova A.I., Vasylyk Ya.V. et al. Principles of X-ray diffractometry of perturbed surface layers and non-uniformly distributed microdefects commensurate with extinction length in single crystals. Metallofiz. Noveishie Tekhnol. 2012. 34, No 6. P. 787-798 (in Russian).

29. Molodkin V.B., Nizkova A.I., Vasylyk Ya.V. et al. New possibilities for X-ray diffractometry of microdefects' structure evolution in silicon crystals after irradiation with high-energy electrons. Metallofiz. Noveishie Tekhnol. 2012. 34, No 7. P. 989-1002 (in Russian).

30. Talanin I.E. Mechanism of Formation and Properties of Growth of Microdefects in Dislocation-Free Silicon Single Crystals. Thesis of Doctor of Physics and Mathematics Sciences. Chernivtsi National University, 2005 (in Russian).

31. Molodkin V.B., Olikhovskii S.I., Dmitriev S.V. et al. Dynamical effects in the integrated X-ray scattering intensity from imperfect crystals in Bragg diffraction geometry. I. Semi-dynamical model. Acta Crystallogr. A. 2020. 76. P. 45-54.

https://doi.org/10.1107/S2053273319014281.

\section{Authors and CV}

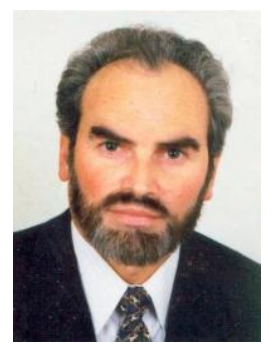

Vadim B. Molodkin, Doctor of Sciences (Physics and Mathematics), Corresponding Member of NAS of Ukraine, Professor, Chief Staff Researcher of the Department of Physics for Multiparametrical Structural Diagnostics at the G. Kurdyumov Institute for Metal Physics, NASU. Author of more than 300 publications. His research interests include solid-state physics, dynamical statistical theory of radiation scattering in crystals with defects, alloys, multilayer inhomogeneous systems with macrodeformations and microdefects.

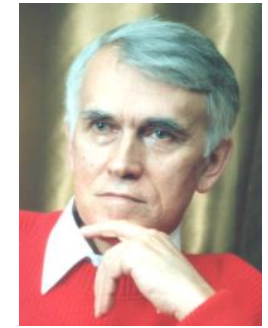

Volodymyr Yu. Storizhko, Doctor of Sciences (Physics and Mathematics), Academician of NAS of Ukraine, Professor, Director of the Institute of Applied Physics. A well-known scientist in the field of experimental nuclear physics of low and medium energies Author of more than 300 publications. His research interests include elementary particle physics, nuclear physics and physics of low and medium energies.

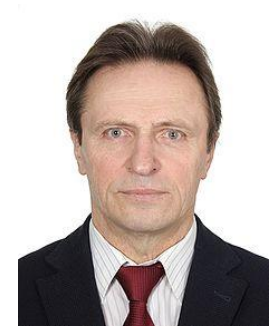

Vasyl P. Kladko, Doctor of Sciences (Physics and Mathematics), Corresponding Member of NAS of Ukraine, Head of the Department of Structural and Elemental Analysis of Materials and Systems at the V. Lashkaryov Institute of Semiconductor Physics. Author of more than 300 publications. His research interests include solid-state physics, dynamical theory of diffraction of radiation, X-ray optics, X-ray diffraction analysis of semiconductor crystals, hetero- and nanosystems.

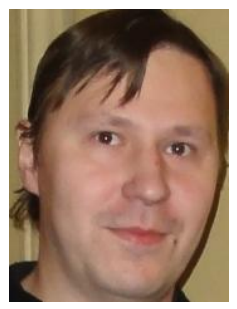

Vyacheslav V. Lizunov, Doctor of Sciences (Physics and Mathematics), Head of the Department of Physics for Multiparametrical Structural Diagnostics at the G. Kurdyumov Institute for Metal Physics, NAS of Ukraine. Author of more than 70 publications. His research interests include solid-state physics, dynamical theory of diffraction, phase-contrast imaging, coherent X-ray diffractive imaging, strongly correlated materials.

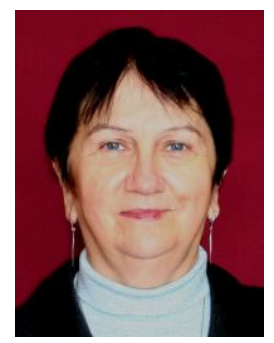

Hanna I. Nyzkova, Doctor of Sciences (Physics and Mathematics), Professor, Leading Researcher of the Department of Physics for Multiparametrical Structural Diagnostics at the G. Kurdyumov Institute for Metal Physics, NAS of Ukraine. Author of more than 100 publications. Her research interests include solid-state physics, dynamical theory of diffraction, integrated diffractometry.

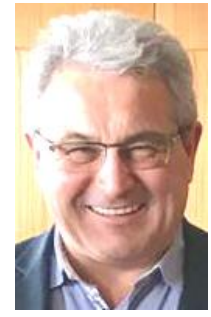

Mykola G. Tolmachev, $\mathrm{PhD}$ in Physics and Mathematics. Author of more than 50 publications.

His research interests include: solidstate physics, experimental dynamical diffractometry of single crystals with microdefects. 


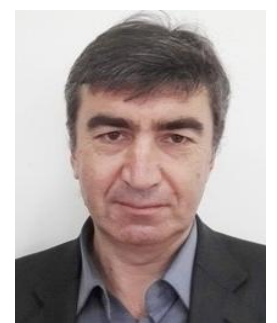

Olexandr Yo. Gudymenko, $\mathrm{PhD}$ in Physics and Mathematics, Researcher at the Department of Structural and Elemental Analysis of Materials and Systems, V. Lashkaryov Institute of Semiconductor Physics. Author of more than 60 publications. His research interests include: solid-state physics, dynamical theory of diffraction of radiation, X-ray optics, X-ray diffraction analysis of semiconductor crystals, hetero- and nanosystems, XRD analysis of materials, X-ray reflectometry of thin films.

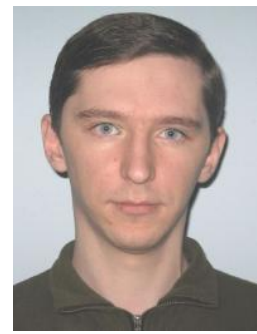

Serhii V. Dmitriev, PhD in Physics and Mathematics, Senior Researcher at the Department of Physics for Multiparametrical Structural Diagnostics, G. Kurdyumov Institute for Metal Physics. Author of more than 50 publications. His research interests include dynamical theory of X-ray diffraction, theory of extinction effects of diffuse scattering.

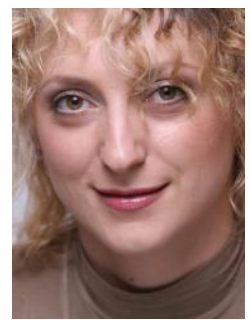

Iryna I. Demchyk, $\mathrm{PhD}$ in Physics and Mathematics, Researcher at the Department of Physics for Multiparametrical Structural Diagnostics, G. Kurdyumov Institute for Metal Physics. Author of more than 20 publications. Her research interests include the methods of total integrated intensities of dynamical scattering.

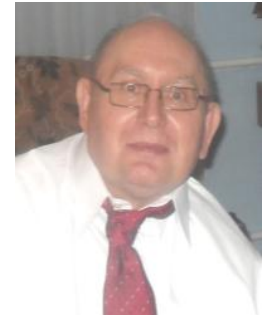

Stephan I. Olikhovskii, Doctor of Sciences (Physics and Mathematics), Professor at the Department of Physics for Multiparametrical Structural Diagnostics, G. Kurdyumov Institute for Metal Physics, NASU. Author of more than 200 publications. Main research interests are in the dynamical theory of X-ray diffraction by imperfect crystals and its applications to characterization of defects and strains in real single crystals and multilayer structures, both as-grown and modified by thermal treatment, ion implantation, etc.

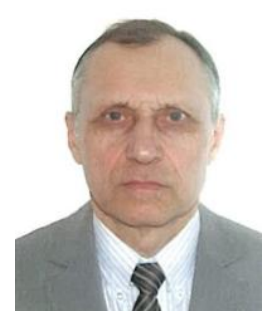

Yevhen I. Bohdanov, PhD in Physics and Mathematics, Researcher at the Department of Physics and Radiometry of Non-Equilibrium Transport Phenomena at the G. Kurdyumov Institute for Metal Physics. Author of more than 50 publications. His research interests include materials science, manufacture of single crystals and research of their properties.

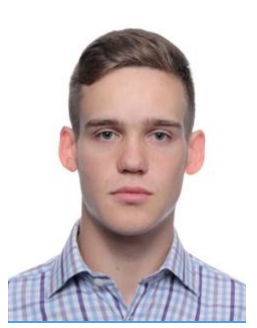

Bohdan I. Hinko, $2^{\text {nd }}$ year student of Faculty of Radiophysics, Electronics and Computer Systems at the Taras Shevchenko National University of Kyiv. His research interests include solid-state physics, dynamical diffractometry.

\section{Новітні можливості фазоваріаційної структурної діагностики багатопараметричних монокристалічних систем $з$ дефектами}

В.Б. Молодкін, В.Е. Сторіжко, В.П. Кладько, В.В. Лізунов, Г.І. Низкова, О.Й. Гудименко, С.Й. Оліховський, М.Г. Толмачов, С.В. Дмітрієв, І.І. Демчик, С.І. Богданов, Б.І. Гінько

Анотація. Установлено принципово нові особливості та фізичну природу зумовлених ними можливостей цілеспрямованого впливу взаємопов'язаних варіацій різних умов експерименту на зміни вибірковості чутливості азимутальної залежності повної інтегральної інтенсивності динамічної дифракції до різних типів дефектів у монокристалах. У результаті запропоновано вдосконалення і підвищено ефективність використання розроблених авторами раніше “фазоваріаційних” принципів діагностики. Зокрема, на основі запропонованого підходу встановлено наявність додаткових типів дефектів у досліджуваних монокристалах та визначено їх параметри (розміри та концентрації). Одержані результати дозволили забезпечити додаткові чутливість та інформативність фазоваріаційної структурної багатопараметричної неруйнівної діагностики монокристалічних систем $з$ дефектами декількох типів.

Ключові слова: динамічна дифракція, рентгенівське випромінення, фазоваріаційна діагностика, азимутальні залежності, дефекти. 